\title{
Cross-Cultural Variation of Politeness Orientation \& Speech Act Perception
}

\author{
Nisreen Naji Al-Khawaldeh \\ University of Bedfordshire \\ Leicester, United Kingdom \\ E-mail: nisreen.al-khawaldeh@beds.ac.uk \\ Vladimir Žegarac \\ University of Bedfordshire \\ London, United Kingdom \\ E-mail: vladimir.zegarac@beds.ac.uk
}

Received: 27-02-2013

Accepted: 06-04-2013

Published: 01-05-2013

doi:10.7575/aiac.ijalel.v.2n.3p.231

URL: http://dx.doi.org/10.7575/aiac.ijalel.v.2n.3p.231

\begin{abstract}
This paper presents the findings of an empirical study which compares Jordanian and English native speakers' perceptions about the speech act of thanking. The forty interviews conducted revealed some similarities but also of remarkable cross-cultural differences relating to the significance of thanking, the variables affecting it, and the appropriate linguistic and paralinguistic choices, as well as their impact on the interpretation of thanking behaviour. The most important theoretical finding is that the data, while consistent with many views found in the existing literature, do not support Brown and Levinson's (1987) claim that thanking is a speech act which intrinsically threatens the speaker's negative face because it involves overt acceptance of an imposition on the speaker. Rather, thanking should be viewed as a means of establishing and sustaining social relationships. The study findings suggest that cultural variation in thanking is due to the high degree of sensitivity of this speech act to the complex interplay of a range of social and contextual variables, and point to some promising directions for further research.
\end{abstract}

Keywords: Linguistic Variation, Cross-Cultural Pragmatics, Speech Act of Thanking, Perceptions of Politeness

\section{Introduction}

A cross-cultural comparative study of the ways native speakers perceive linguistically appropriate ways to express gratitude in two cultures can help develop better models of communicative competence relating to the speech act of thanking. It could also lead to devising strategies for improving non-native speakers' production and reception of this speech act (Davies, 2000). It is not surprising that people who live in different cultures have different perceptions about the way thanking (i.e. the linguistic expression of gratitude) should be performed in interpersonal communication. Apte (1974) observes that gratitude is frequently expressed in situations where goods are swapped between family members and close friends in American society, but not in the Hindi and the Marathi cultures, where thanking would be viewed as ungrateful or even insulting in situations of this type, because the actions thanked for are presumed to be social duties accepted and expected by the participants. The same is true of Eastern cultures where thanking a close friend or relative who usually provides assistance would be perceived as demeaning to their face (Ervin-Tripp et al., 1995). However, rather general observations such as these need to be explored in more detail by considering insiders' perceptions relating to the intricate interplay of many factors in a wide range of communication situations.

Hymes (1971) concludes that expressing thanks in most English speaking cultures seldom involves establishing social reciprocity or indebtedness though it is common in all daily situations. In Hinkel's (1994) view, thanking in the English culture is the fulfilment of a social expectation, as politeness in this culture is not regulated or controlled by other features of the situation, such as indebtedness, gender, social status or age (Hymes, 1971). Intachakra (2004) found that Thai and English cultures vary in the accessibility of thanking strategies and that "Thais may not utter thanks as effusively as the British" (p.58) due to their preference for expressing gratitude through their actions, rather than signalling it verbally.

Cross-cultural variation is also evident in the cultural weightiness of situational and contextual variables. Thus, Yang (1986) found that social status in the Korean culture largely determines the way people thank: gratitude is not expressed (and is not expected to be expressed) as readily by high social status people as by those of a lower social status. Likewise, in Indonesia linguistic politeness is used less by high social status individuals (Errington, 1984). SmithHefner (1988) suggests that due to the fact that an individual's perceived social position is habitually bound to age, gender and self-identity, extremely elaborate and intricate tactical rules control the use of all linguistic formulae and that the speech act of thanking is not an exception. This is also evident in the Spanish culture where some specific types 
of actions (e.g. in service contexts) do not call for linguistic expressions of gratitude (Pablos-Ortega, 2010). Eisenstein and Bodman $(1986,1993)$ point out that linguistic formality differs considerably depending on whether the situation itself is seen by the participants as informal and that the length of utterances is a reflection of the degree of the speaker's indebtedness, with shorter thanking utterances sometimes signaling greater social distance between the interlocutors. All studies of thanking indicate that there are underlying complex rules for expressing thanking adequately. In other words, the speech act of thanking is institutionalized in different ways across cultures.

An important reason for carrying out the present study of the speech act of thanking is the importance of this speech act for establishing and maintaining social bonds (Intachakra, 2004). The sensitivity of rapport management to appropriate thanking has been recognized in Brown and Levinson's (1987) approach to linguistic politeness where thanking is identified as a typical facethreatening act. These authors argue that people who engage in communication usually collaborate to maintain each other's face. Thus, speakers should be aware of when and how to thank in their culture and other target cultures in order to maintain each other's face as well as their own. This suggests that thanking can be considered both as based on some universal features of human communication and cognition, and as a social norm/convention. These assumptions are not incompatible. They show that the ways thanking is institutionalized in different cultures (the culture-specific social norms of thanking) should be explained as resulting from the interplay between some universal features of social interaction and some culture-specific factors (values, attitudes). In view of this, and the fact that thanking serves a societal function, people should not only know the semantic formulae essential for expressing gratitude, but they should also understand and learn the culture-specific rules and norms for thanking in the target language, including those about the appropriate times and ways to use such formulae (Blum-Kulka and Olshtain, 1984).

Most research on the speech act of thanking within pragmatics focuses on the production of this speech act and on linguistic strategies used to express gratitude (e.g. Cheng, 2005). Few studies have considered the causal role of social and contextual factors in the interpretation and the performance of the speech act of thanking. The present study is an attempt to fill this gap by investigating native speakers' perceptions of thanking behaviour in two cultures.

Expressing thanking is greatly valued in Arab cultural groups as it plays an important role in establishing and maintaining on-going social reciprocity and good relationships between interlocutors which are very important to these groups' members (Samarah, 2010). Nydell (1987) and EL-Sayed (1991) observe that the point of exchanging thanks is the acceptance of the speaker within a social group, rather than the making of offers as tokens of gratitude (which, consequently, should not be taken literally). Due to the importance of face-saving in the Arabic culture, adequate linguistic expressions of gratitude are highly valued. In particular, in most cases thanking signifies indebtedness, as illustrated by the expression "Al' ashani" which means "for my sake". This idea is interesting because it reflects the speaker's underlying good will, whose importance is often overlooked in studies of thanking. It seems that Western egalitarianism presupposes that everything one does for another person involves some degree of imposition and is therefore worth being thanked for, but lacks the further assumption that personal 'sacrifice' is actually motivated by good will towards the other person. In Arabic cultures (and in some other cultures for, that matter) it is assumed that the main motivation for doing things for others and thanking them for giving things is one's good will towards them, a generous disposition, rather than a sense of obligation.

Despite its importance, the speech act of thanking in Arabic speaking cultures has not been investigated extensively, and no research has been conducted on the way thanking is perceived in the Jordanian Arabic culture. As Feghali (1997) points out, research on Arab cultural-communication patterns has been entrenched in concise and dated anecdotes. Moreover, as Shouby (1951) observed many years ago, research on Arabic culture has tended to lump all Arabic-speaking countries together. The present study makes a contribution to the field of intercultural pragmatics by considering the speech act of thanking in particular cultures, those of Jordan and England, in a way which addresses some important gaps in and limitations of previous research.

\section{Methodology}

\subsection{Research aim}

This study investigates the similarities and the differences between Jordanian and English perceptions of expressing thanking. In particular, we explore peoples' general awareness of the importance of thanking, we consider how the members of each of the two societies decide whether thanking is appropriate and, if so, how this speech act should be performed, what the causes of occasional awkwardness in the production and reception of thanking behaviour are, and the extent to which people are conscious of the social rules and the situational factors which inform and guide thanking behaviour. The study focuses on the interlocutors' sensitivity to relevant situational and social factors (such as the participants' characteristics and the content of thanking expressions) which influence the observed variation in the linguistic expression of gratitude.

\subsection{Research subjects}

The subjects were male and female native speakers of Arabic and English. They were 20 British and 20 Jordanian postgraduate students studying on Sciences or Humanities study programmes in Jordan and the United Kingdom. None of the subjects had lived outside Jordan and the United Kingdom, respectively, or had any experience of cross-cultural studies. The subjects' age-range was twenty one to thirty four. 


\subsection{Research instruments}

All data were collected by semi-structured interviews and these were audio-taped. The semi-structured interview was preferred over other research methods because it can yield data that better reflect peoples' perceptions of both their thanking behaviour and the social realities associated with it. This method facilitates identifying and analysing the underlying motives of thanking behaviour and related factors. It also makes possible the collection of rich data (about feelings, opinions, and factual assumptions), providing valuable evidence for understanding speech act performance in relation to the underlying competence in a theoretically plausible way. Another advantage of the semi-structured interview is that it allows for in-depth probing, as the researcher can freely introduce ad hoc follow up questions during the interview.

\subsection{Data analysis}

Strauss and Corbin's (2004) open coding qualitative analysis of the interview data was adopted for classifying the 'raw' data into meaningful concepts which were then grouped into relevant categories. This helped reduce the overall number of data units and made the examination and the comparison of the data easier. Following Strauss (1987), the process of coding qualitative data included: open coding, axial coding and selective coding. Open coding involves breaking down the collected data into distinctive parts, trying to discover relevant concepts, identifying categories to reduce the vast array of data into controllable categories. This theory-neutral approach seemed preferable to Miles and Huberman's (1994) method which requires having an already prepared table of categories in light of which the new data is coded, because this increases the likelihood of failing to identify novel relevant concepts that might be evidenced by the newly collected research data. Axial coding involves trying to find linkages among the new labelled categories, thinking about causes and conditions, and combining interdependent concepts into one theme or splitting some concepts into subcategories. Selective coding includes reviewing the primary themes to discover an overarching theme. In the present study, this type of coding helped detect any differences in the participants' perceptions of thanking and the related politeness orientations, as well as tracing any differences in the thanking behaviour of Jordanian men and women.

\section{Results and Discussion}

\subsection{The perception of the significance of thanking}

The analysis of the data revealed few similarities and many noticeable differences in the perception of the speech act of thanking in the cultures of Jordan and England. This is not surprising as they have very different cultures and languages. The results showed that each native group was consistent in its use of thanking expressions in relation to cultural norms and values. This supports Eisenstein and Bodman's (1986) notion of the "mutually-shared script" (172) among the members of the same group and Hymes' (1972) view that each speech community has its own preferred means of articulating and expressing particular ideas which are embedded in conventions of language use shared by its members. This finding is also consistent with Leech (1983) and Eisenstein and Bodman (1986) who point out that thanking is a frequent everyday speech act and a politeness marker for showing gratitude.

Table 1. Significance of thanking

\begin{tabular}{|c|c|c|c|c|}
\hline \multirow{2}{*}{ Subjects } & \multicolumn{4}{|c|}{ Significance } \\
\cline { 2 - 5 } & Politeness implication & Religious implication & Social and cultural norm & Social implication \\
\hline English & $100 \%$ & $0 \%$ & $100 \%$ & $20 \%$ \\
\hline Jordanians & $100 \%$ & $90 \%$ & $55 \%$ & $100 \%$ \\
\hline
\end{tabular}

Table 1 show that both groups emphasized the significance of expressing gratitude as a way to show appreciation for the kindness and helpfulness of others. They stated that "manners cost nothing and everyone likes to feel appreciated". That is, by thanking somebody we implicitly or explicitly acknowledge that we are indebted to one or more other people and that we accept to return the favour.

In particular, all English participants highlighted the idea that expressing thanks is a sign of politeness and a conventional social norm and cultural value. They pointed out that thanking is a matter of common decency and manners taught at home and school from an early age. They also pointed out that breaking this convention is a sign of rudeness and indicates ungratefulness and underappreciation of the favour, impoliteness and lack of basic manners, potentially leading to bad feelings, anger, and disappointment, as it breaks the rule: "Deal with others as you want them to deal with you".

All Jordanian participants said that thanking is a good indication of politeness, a reflection of the personal image which facilitates establishing and maintaining good social relationships. As many as 16 Jordanian subjects stated that their deep commitment to thanking was rooted in strongly held religious beliefs such as "Those who do not thank humans do not thank God". Therefore, failing to express appreciation would be unacceptable as it offends God and definitely results in embarrassment, isolating the person from the group and putting their self-image at risk. This in turn has an adverse effect on social rapport, which is built largely on sharing politeness and mutual respect. In contrast to the British, all Jordanians emphasized their feeling of being aggrieved or less inclined to help in the future as another negative consequence of the interlocutor's failure to show appreciation. 
This finding is consistent with Kumar's (2001) observation that expressing thanks is a universal speech act which shows cultural variation. This result is in line with Hinkel's (1994) view of thanking as fulfilling a social expectation, as the focus of early upbringing and education of children in England focuses on the importance of expressing gratitude and learning polite behaviour, in general, because failing to express gratefulness is seen as a sign of rudeness and ingratitude. As Kumar (2001) observes, being deprived of deserved appreciation results in feeling cheated and betrayed.

Jordanian participants emphasized the powerful impact that expressing or failing to express appreciation has on establishing and keeping good relationships with others. This is due to the fact that they value showing care for the feelings of others, so behaving politely is very important for establishing, maintaining and enhancing social relationships in the Jordanian culture (as well as in other Arab societies). Thus, failure to show gratitude would most likely lead to the feeling of reluctance to help others and have relationships with them in the future. This result is in line with the finding of El-Sayed (1991) and Intachakra (2004) that thanking plays a momentous role in engendering and keeping closer and stronger social relationships. It establishes on-going social reciprocity and cohesive group membership ties in a society. Samarah (2010) points this out as a remarkable difference between Arabic and Western societies, as Arab people seem to be more concerned about saving other's face and establishing on-going social relationships. This is readily explained by Brown and Levinson's (1987) framework in which concern for maintaining the interlocutor's face plays a central role in explaining linguistic politeness. It is also consistent with Hofstede's (1991) Individualism-Collectivism dimension of culture. In collectivist societies people are incorporated into strong and cohesive in-groups, so it is to be expected that linguistic politeness, including thanking, should play a major role in strengthening social cohesion. Scollon and Scollon (1995) point out that the main concern in collectivistic cultures is for the effects of individuals' actions on their group, as opposed to individualistic cultures, where freedom of activity is more important. This finding is also compatible with Locher and Watts' (2005), Spencer-Oatey's (2005), and Arundale's (2006) perspectives on interactional and relational functions of speech acts. However, the present study data seem to show that thanking should not be viewed as intrinsically face-threatening (pace Brown and Levinson, 1987), because its basic function is to establish and sustain social relationships, so thanking is generally desirable to both the thanker and the thankee. In Jordan, people seem to "have absorbed a repertoire of divine sentiment into their daily speech, assigning Allah's influence over every area of their lives" (Morrow, 2006: 203) and view thanking behaviour as required by God. This is difficult to reconcile with the view that thanking is intrinsically face-threatening. Moreover, although face-threatening behaviour is generally very noticeable, neither the English nor the Jordanian subjects interviewed for the present study seem to perceive thanking as an imposition on the thanker.

\subsection{The impact of social and contextual variables on thanking}

The data revealed a number of social and contextual variables that might influence the participants' thanking style. In both native groups, social familiarity and degree of imposition were found to be the most significant variables. This supports Coulmas' (1981) claim that, although thanking strategies and proper responses vary depending on the type of gratitude object, interpersonal relations between the interlocutors still play a significant role. The findings are also in line with Blum-Kulka and House (1989) and Kasper and Rose (2002) who argue that societies differ in their assessment and weighting of contextual and social variables and cultural values, such as those concerning their members' rights and duties, obligations, social power, social distance age and gender. Cross-cultural variation in the speech act of thanking, and the intricate interplay of these contextual and social variables in communication make the choice of appropriate thanking expression difficult. This often leaves speakers somewhat embarrassed and unsure as to whether they have performed the speech act appropriately. The data which shows that both groups vary in their evaluations of some contextual and social variables is presented in Table 2.

Table 2. Contextual and social variables

\begin{tabular}{|c|c|c|c|c|c|c|}
\hline \multirow{2}{*}{ Subjects } & \multicolumn{6}{|c|}{ Contextual and social variables } \\
\cline { 2 - 7 } & Degree of imposition & Social status & Social familiarity & Gender & Age & Personality \\
\hline English & $100 \%$ & $10 \%$ & $75 \%$ & $0 \%$ & $0 \%$ & $0 \%$ \\
\hline Jordanians & $100 \%$ & $100 \%$ & $90 \%$ & $95 \%$ & $95 \%$ & $90 \%$ \\
\hline
\end{tabular}

Both groups of respondents consider the degree of favour and social familiarity as definite sources of influence. In particular, all English and Jordanian participants perceive the degree of the imposition on the person who did the favour as having the most important impact on thanking. They said that the degree of thanking should match the favour: the bigger the favour, the greater the appreciation should be. Although overstating gratitude and using various elaborate and embellished thanking expressions is preferred in response to having received great help, Jordanian and English participants seem to vary in their judgements about the extent to which overstating one's gratitude is acceptable. The English participants reported that they would use the full expression "Thank you very much" and/or "I really appreciate that" or seldom repeat a thanking expression, while Jordanian participants emphasized that they would use diverse strategies such as "Thank you very much", "I can't thank you enough", "This is really kind of you", as well as using a repetition, and adverbs of degree to convey the extent of their gratitude, along with prayers (e.g. "Jazaka Allah", "May Allah reward you") and stating the addressee's names and titles.

Despite emphasizing the probable impact of social familiarity, the two groups had different perceptions concerning appropriate stylistic choices and the need for thanking in various social contexts, as shown in the Table 3. 
Table 3. Thanking in diverse social contexts

\begin{tabular}{|c|c|c|c|c|}
\hline Subjects & \multicolumn{4}{|c|}{ Social context of thanking } \\
\hline & Family & Friends & $\begin{array}{c}\text { Service } \\
\text { encounters }\end{array}$ & Formal encounters \\
\hline English & $100 \%$ & $100 \%$ & $100 \%$ & $100 \%$ \\
\hline Jordanians & $40 \%$ & $45 \%$ & $20 \%$ & $100 \%$ \\
\hline
\end{tabular}

Although thanking is highly favoured within the Arabic context, Table 3 shows that it is frequently expressed among family members and friends. In other words, all participants pointed out that the closer the relationship is, the less thanking is expected and expressed. Moreover, 16 Jordanian participants reported that it is culturally not obligatory to thank people in service encounters and that most people, especially those with a lower level of education, would rarely convey thanks to a grocery store worker, a bus driver, or a cashier. However, all participants affirmed the necessity to thank unfamiliar people with whom they have a formal relationship, although the degree of gratitude expressed differs from one situation to another. Furthermore, any thanking in such service encounter situations should be kept brief and consist of only the most essential formulaic thanking expressions such as "Yeslamo" ("Thanks") or nonverbal "lifting a hand". They also added that people working in such jobs do not expect or wait for others to thank them.

Expressing gratitude is very common among the English family's members, friends and people in service encounters. All of them would thank regardless of the thankee's occupation or familiarity with the thanker. However, eighteen English participants said that they would go into detail when thanking a familiar person, as opposed to a stranger, unless there is a high degree of imposition, in which case they would try to repay the stranger for his or her kindness in some way, most likely by offering a small sum of money.

Table 2 also shows a remarkable difference in considering the influence social status on thanking. All Jordanian participants stated that they would give more attention when thanking a high status person than people of lower status. This could be referred to as absolute social status, which means that one would thank more elaborately people of high status, regardless of whether their status is higher than one's own. For example, titles and names such as "professor Omar" should be used in addition to elaborate thanking expressions. In contrast, nineteen English participants said that both high status persons and persons of lower or equal status would receive the same degree of verbal gratitude.

However, all English and Jordanian participants emphasized that an unfamiliar or a high social status person should be thanked in a formal way, e.g. by saying: "Thank you very much" "I appreciate that" smiling and sometimes more formally by shaking hands. Thanking a friend is typically informal: "Cheers" "Thanks", "Thanks a lot", "Ta" or only using adjectives such as "Brilliant" or "Great" and their equivalents in Arabic. Furthermore, while the words "Appreciate" and "Thanks" can be used by English participants interchangeably regardless of familiarity, some Jordanians highlighted the formality of the word "Appreciate" "Agadir") which is mostly used in more formal situations, e.g. when thanking one's boss, rather than, say, one's friend.

In contrast to the English participants, Jordanians highlighted the considerable effect of the interlocutor's personality, gender and age on their thanking style, as shown in Table 2. In particular, 18 participants mentioned that they would go further in their thanking, e.g. initiating small talk, (introducing themselves) and suggesting establishing future relationships or even talking about their future expectations only if they know in advance that the addressee is friendly and eager to adapt to other participants in social situations. 16 interviewees also revealed that they thank older people more than children who are seldom thanked and mostly by making nominal compliments, such as "Good boy". 19 Jordanians said that males thank each other less than females do each other.

Both groups reported that the greater the favour received is the more elaborate thanking should be. This is due to the fact that people feel more indebted for receiving favours which require more effort and time. They aim to communicate their appreciation for received favours in culturally appropriate ways. Of course, there is cultural variation in what counts as appropriately elaborate thanking. The findings of this study strongly support Wolfson's (1989) observation that the speakers' perceived degree of indebtedness determines the length of the thanking utterances, while there is considerable cultural variation in the way the importance of these factors is assessed.

The present study also supports the widely held perception that thanking is a common feature of English society: between friends, family members, and interactants in various service encounters. This could be attributed to respect for personal autonomy, and the consequent need to acknowledge indebtedness for relatively small favours between close friends or family members. In contrast to the English, Jordanians do not perceive close friends as autonomous individuals but as co-dependents with a mutual obligation to support each other in various ways, so gratitude is neither expected nor communicated even for relatively costly favours. Close friends are considered family members. They rely on each other most of the time and the closeness of the relationship is reflected in the use of family terms "brother" and "sister" when referring to them. Moreover, favours are made as actions of personal generosity rather than (facethreatening) impositions, especially in informal situations. Even when gratitude is expressed among close friends, it is communicated more succinctly than in formal situations, where thanking is expected, highly valued and more elaborate. As favours between close friends and relatives are exchanged regularly and can be taken for granted, there is no need to communicate one's gratitude for them. If thanks are given, this is done in a brief, casual way, by paying a conventional compliment or using a formulaic expression such as: "May God reward you". This is likely to happen in such familiar situations in a society like Jordan characterized by a comparatively relational group mentality, in contrast to Western 
societies which are much more individualistic. Unlike the Jordanian participants, the English participants believe that even a friend is under no obligation to help, and they view this expectation as a socially unacceptable lack of respect for personal autonomy. These findings are similar to those of Eisenstein and Bodman (1986) who found a significant correlation between the length of thanking expressions and the social distance between the interlocutors. The use of shorter thanking expressions tends to reflect greater social distance between the speaker and the hearer. Another study with similar findings is Apte's (1974) research on South Asian Languages (Hindi and Marathi), where thanking is not preferred, and doing the favour is perceived as a duty. In a nutshell, existing research shows that thanking is very strongly related to indebtedness, with considerable cultural variation about how the extent of personal debt for a favour is assessed.

Unlike those of the English participants, Jordanian participants' assessments of indebtedness and appropriate thanking strategy also take account of some other variables, most notably: the thankee's social status, gender, age and personality. This finding seems inconsistent with Cheng (2005) who imputes the incongruence between thanking and the sense of social reciprocity or indebtedness mainly to the considerable importance of the age factor. However, the present study shows that there are a number of other substantial variables. In Jordan, high social class and old people should be thanked with a high level of care and respect. This can be ascribed to the influence of social traditions and religion which place some restrictions on mixed-gender and mixed-age interaction. This present study findings are in line with Hymes (1971) and Hinkel (1994) who conclude that politeness norms, including those about expressing gratitude, in English speaking cultures are not controlled by other features of the situation such as "indebtedness, social status and reciprocity, gender, or age" (p. 76). In addition, the findings support Takahashi and Beebe's (1993) observation that social status is more essential from the Asian (in his case Japanese) viewpoint than that of Anglo Saxon (in his case USA) culture. However, it contrasts with Okamoto and Robinson's (1997) results where "Thank you" is often used when communicating with high-status interlocutors within the British context, as all people are treated equally in terms of linguistic politeness.

In addition, Jordanians believe that high status people and old people should be thanked usingelaborate linguistic expressions of gratitude. The finding is consistent with Smith-Hefner's (1988) observations that older people are treated with respect and the individual's perceived social position is habitually bound to age, gender, and self-identity, and that extremely elaborate and intricate rules control the use of all linguistic politeness markers. The finding regarding the unlikely communication of gratitude by high social status individuals to those of lower status in Jordanian culture appears similar to research findings on other Asian cultures such as those of Indonesia (Errington, 1984) and Korea (Yang, 1986), where the expectation that feelings of gratitude will be communicated linguistically by individuals of higher social status to those of lower status is very low or non-existent. Thus, it seems that social status is generally very important in Asian cultures and that the linguistic communication of gratitude in these cultures is also very sensitive to the social social-status differential between the interlocutors. In Jordan, old people express their thanks in a different way from younger people. They tend to use blessings and repetitive thanking. In general, Jordanians expect and like to receive blessings and titles such as "Ya ibni", "My son" and "Ya binti" "My daughter" as typical forms of thanking by old people, even those with whom they do not have close social links. These modes of address are considered polite and they are expected even when addressing non-relatives.

\subsection{The type and length of thanking expression}

We now turn to perceptions relating to the type of thanking expressions used in the two cultures. The English participants seem to differ significantly from Jordanians in terms of strategy type and length of thanking expression, as shown in Table 4.

Table 4. Thanking type

\begin{tabular}{|c|c|c|c|c|}
\hline \multirow{2}{*}{$\begin{array}{l}\text { Subjects/ } \\
\text { Thanking } \\
\text { strategies }\end{array}$} & \multicolumn{3}{|c|}{ Thanking type } & Length \\
\hline & Verbal strategies & Non-verbal strategies & Others & \\
\hline English & $\begin{array}{l}\text { Direct (Thanking, } \\
\text { appreciation, repayment) } \\
100 \%\end{array}$ & $\begin{array}{l}\text { - Smiling- } \\
\text { shaking hands, high } \\
\text { tone, kissing, eye } \\
\text { contact }(90 \%) \\
- \\
\text { "Thumb up", } \\
\text { "Hand up", "Flash } \\
\text { lights" (20\%) }\end{array}$ & $\begin{array}{l}\text { - } \\
\text { phone messages or } \\
\text { calling }(75 \%) \\
-\quad \text { Gifts }(70 \%)\end{array}$ & $\begin{array}{l}\text { Short thanking } \\
\text { semantic formula } \\
\text { is adequate } 100 \%\end{array}$ \\
\hline Jordanians & $\begin{array}{l}\text { A mixture of direct and } \\
\text { indirect (the above } \\
\text { besides compliments, } \\
\text { prayers, small talk, } \\
\text { apology, using } \\
\text { titles...) } 85 \%\end{array}$ & $\begin{array}{l}\text { Restricted } \\
\text { Smiling, shaking hand, } \\
\text { high tone }(85 \%) \\
- \\
\text { "Hand up" "Flash up", } \\
\text { lights" }(55 \%) \\
\text { - "Nodding their } \\
\text { heads" with putting } \\
\text { hand on the chest (35\%) }\end{array}$ & $\begin{array}{l}\text { - Face- face is } \\
\text { preferred }(85 \%) \\
-\quad \text { Offering } \\
\text { food especially (at } \\
\text { home) } 100 \%\end{array}$ & $\begin{array}{l}\text { Lengthy thanking } \\
\text { (intensified and } \\
\text { repeated) semantic } \\
\text { formula is required } \\
(90 \%)\end{array}$ \\
\hline
\end{tabular}

While all English participants appeared to prefer simple thanking and direct thanking expressions such as "Thank you very much" and "I highly appreciate your help", in the Jordanian culture the use of complex direct and indirect 
thanking expressions is very common. For example, along with conveying thanking explicitly, 17 Jordanian participants disclosed their great preference for using implicit expressions such as "Ghallabnak?!" (literally, "We tire you") which is not a question but a set way of thanking, being and "Ana ajez a shokrak", (literally, "I am incapable of thanking you"). They also have a strong preference for expressing their positive feelings, especially complimenting others and praising

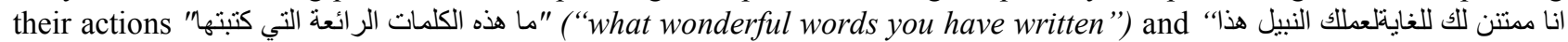
("I am extremely indebted to you for your noble deed"). As opposed to the British, all Jordanian participants also showed a strong preference for using and receiving "Prayers/Benediction" expressions which include references to Allah' ("God"), such as جزاك اله كل خير ("jazaka Allah khayr"; "May God reward you”) among many other religious expressions which are typical features of their thanking style.

17 participants prefer thanking by using a mixture of speech acts such as "thanking with a sincere apology" and "thanking and compliment" or even "appreciation, repayment, prayers and apology" along with titles when appropriate. From a pragmatic point of view, such expressions enable speakers to genuinely and sincerely express their feelings of gratitude, because they are more informative as they provide (additional) reasons for thanking.

15 English participants stated that sending a thanking email or phone message is quite common, and is accepted in their culture as another means of showing gratitude. In contrast to the English participants, 17 Jordanians revealed that they should go in person to convey their gratitude instead of sending a "thank you" email message or phoning, which is sometimes considered impolite. Unlike the English, all Jordanians revealed that offering food, especially to an unfamiliar and high status person who has been helpful, (e.g. inviting them to dinner) is culturally favoured as a sign of hospitality, especially in situations where merely giving a present may be deemed impolite. However, 14 English participants indicated that they would offer gifts to return a favour to someone they know only superficially, especially if the favour was major. However, lavish gift giving to less familiar people is deemed inappropriate.

Table 4 shows that both cultures also differ in the degree of gratefulness, the way and the extent to which they show their gratitude. While 18 Jordanians prefer various lengthy repetitive, intensified, expressions to match the degree of gratefulness and show sincere appreciation, all the English participants would generally accept "Thank you" or "Thank you very much" as an adequate expression of appreciation. It seems that the English participants do not consider repetition a way to show gratitude. They also use intensifiers to a lesser extent than Jordanians.

Furthermore, the majority of participants in both groups also greatly emphasized the importance of the way thanking is expressed, highlighting the significance of the accompanying tone of voice, facial expressions and body language. These can help differentiate between real appreciation and hypocrisy (when body language accidentally does not match the words) or sarcastic thanks (where the mismatch is evidently intentional). The former are often insincere expressions of gratitude, while the latter are expressions of gratitude which are used to perform some other speech act (e.g. to blame with ridicule and scorn). 15 English and 18 Jordanian participants consider the importance of non-verbal thanking expressions (such as a smile and high tone, kissing, and shaking hands). They are good signs accompanying verbal gratitude expressions in some conversations in the Jordanian context, especially in mixed-gender thanking. Unlike the English participants, the Jordanians stated that facial expressions accompanying the hearer's response for receiving thanks could help them tell whether their thanks have been accepted or not. For example, if they seem disheartened, then the gesture is seen as too small, but if they seem surprised then the gesture is seen as very big. Furthermore, 11 Jordanian and 4 English participants highlighted the significance of signs such as patting on the arm within familiar contexts and "Thumb up", "Hand up", and "Flash lights" when it is impossible to thank verbally, as in the case of driving on the motorway. Only 7 Jordanians mentioned that "nodding their heads", sometimes along with "putting hands up" or putting hand on the chest or head or even "bending their body", are used to communicated a high degree of gratitude.

A major difference between the two cultures concerns handshaking and eye-contact. While 18 English participants revealed that these actions which accompany thanking are highly valued in the English society as indicators of politeness, in the Jordanian culture they are not only insignificant, but are also inappropriate, especially in mixed-gender interaction, and are even considered impolite in many situations.

Jordanians seem to prefer using special elaborate expressions in what outsiders perceive as an extravagant, flowery and grandiloquent way when expressing thanking to show more respect and deference to their interlocutors. This supports Suleiman's (1973) and Zaharna's (1995) characterizations of Arabic communication style as elaborate, flowery, indirect, and repetitious. This could be due to a general cultural preference for using a mixture of various types of thanking, which from the Jordanian perspective indicates sincerity. The present study supports the general observation that thanking forms, rituals and formulaic expressions differ across cultures (Morsi, 2010) as well as Wolfson's (1986: 119) finding about cross-cultural variation in the "distribution and frequencies of occurrence" of speech act strategies. In view of such cultural differences, it is not surprising that the English perceive lengthy thanking expressions as unnecessary and as potentially leading to miscommunication, and that the speaker's 'exaggerated' style is likely to be perceived as a sign of hypocrisy. Overall, the findings strongly point to the need for a better understanding of the social function(s) of thanking and of the culture-specific values and attitudes which inform and guide the performance of this speech act. Haverkate (1988) argues that thanking is a reactive action whose function is to restore equilibrium in the cost-benefit relation among interlocutors. Accordingly, any type of repayment, such as an invitation for a meal or giftgiving, is highly favoured. As Komter (2004: 210) observes: "gratitude is the in-between connecting gift and return gift." These three elements of gift, gratitude, and counter gift constitute the principle of reciprocity. There is interesting cross-cultural variation in what counts as appropriate repayment. While Jordanians have a strong preference for offering 
food, the English favour gift-giving. The observed cross cultural differences in the complexity of verbal expressions for thanking and the kind of repayment gifts versus food) suggest that English (British/Western) culture is oriented towards material rewards (with brief verbal expressions of gratitude and gifts being more valued) while the Jordanian (Arabic) culture is oriented towards symbolic spiritual rewards (hence the prevalence of more complex verbal thanking expressions, conventionalised use of prayers used for thanking, and offers of food, which could be seen as a form of communion between the thanker and the thankee). From a different perspective, it could be argued that the speech act of thanking is not intrinsically face-threatening. In some cultures (e.g. many Western cultures) the act of thanking is seen as an acknowledgement that the thanker is indebted to the thankee, so it is indeed an imposition on the speaker and, therefore, a threat to the speaker's negative face. However, in other cultures, such as Jordan (and other Arabic cultures) the act of thanking itself counts as a repayment for the favour, so it is therefore not intrinsically facethreatening (although it can be face-threatening, say, if the thanker feels they should to offer food to the thankee, despite not having enough to meet their own needs). These suggestions are consistent with Austin (1962) and Searle (1969) who claim that speech acts - and thanking is not an exception - operate by universal pragmatic principles in that thanking serves the same general function across cultures. However, there is considerable cultural variation in the ways thanking is realized and valued.

\section{Conclusion}

The study investigates the similarities and differences in perceptions about thanking in the cultures of Jordan and England. The data collected by semi-structured interviews revealed significant cross-cultural differences in the production and reception of thanking due to cultural differences in a number of social and contextual variables. The findings have some interesting implications for the theoretical pragmatic description and analysis of the speech act of thanking, as well as for the development of communicative competence.

The study findings are compatible with a range of views on thanking found in the literature. However, our data provide little support, if any, for the well-known view that thanking is intrinsically a face threatening act. English informants perceived thanking as socially desirable and costing nothing. Jordanians' perceptions were incompatible with the view that thanking was an imposition on the thanker in their culture (although thanking could involve making particular commitments, which, in some circumstances, could put the thanker to some considerable cost). Our data suggest that it would be worth exploring through further research the hypothesis that cultural variation in thanking concerns both its value and the forms it takes, while this type of speech act is universally a way of regulating social relations by acknowledging debts through communication. While thanking plays an important role in managing social relations, its sensitivity to a complex interplay of various social and contextual variables (including the value that a given society places on thanking) makes the socio-pragmatic competence for performing and interpreting this speech act difficult to develop. The findings presented in this paper take us a step closer to a better understanding of some culture-specific features of thanking and in this way potentially contribute to devising better strategies for the development of communicative competence.

\section{References}

Apte, M. L. (1974). "Thank you" and South Asian languages: A comparative sociolinguistic study. International Journal of the Sociology of Language 3: 67-89.

Arundale, R. B. (2006). Face as relational and interactional: a communication framework for research on face, face work, and politeness. Journal of Politeness Research 2 (2): 193-216.

Austin, J. L. (1962). How to do things with words, Oxford: Oxford University Press.

Blum-Kulka, S. \& House, J. (1989). Cross-cultural and situational variation in requestive behavior in five languages. In S. Blum-Kulka, J. House, \& G. Kasper (Eds.), Cross-cultural pragmatics (pp. 123-154). Norwood, NJ: Ablex

Blum-Kulka, S. and Olshtain, E. (1984). Requests and Apologies: A Cross-Cultural Study of Speech Act Realization Patterns. Applied Linguistics, 5 (3), 196- 213

Brown, P. and Levinson, S. (1987). Politeness: Some universals in language usage. Cambridge: Cambridge University Press.

Cheng, S. W. (2005). An exploratory cross-sectional study of interlanguage pragmatic development of expressions of gratitude by Chinese learners of English. Unpublished PhD Dissertation; The University of Iowa.

Coulmas, Florian, 1981. Poison to your soul: thanks and apologies contrastively viewed. In: Coulmas, F. (Ed.), Conversational Routines. The Hague: Mouton de Gruyter, pp. 69-91.

Davies, E.E. (2000). A contrastive approach to the analysis of politeness formulas. Applied Linguistics, 8, 75-88.

Eisenstein, M., \& Bodman, J. W. (1986). "I very appreciate": Expressions of gratitude by native and nonnative speakers of American English. Applied Linguistics, 7, 167-185.

Eisenstein, M., \& Bodman, J. W. (1993). Expressing gratitude in American English. In G.Kasper \& S. Blum-Kulka (Eds.), Interlanguage pragmatics (pp. 64-81). New York: Oxford University Press.

El-Sayed, A. (1991). Politeness formulas in English and Arabic: A contrastive study. Review of Applied Linguistics, 8990, 1-23.

Errington, J. (1984). Self and self-conduct among the Javanese priyayi elite. American Ethnologist, 11(2), 275-290.

Ervin-Tripp, S., Nakamura, K. \& Guo, J. (1995). Shifting face from Asia to Europe1. Essays in semantics and pragmatics: in honour of Charles J. Fillmore, 32, 43. 
Feghali, E. (1997). Arab culture communication patterns. International Journal of Intercultural Relations, 21, 345-378.

Haverkate, H. (1988). Toward a typology of politeness strategies in communicative interaction. Multilingual-Journal of Cross-Cultural and Interlanguage Communication 7(4): 385-410.

Hinkel, E. (1994). Pragmatics of interaction: Expressing thanks in a second language. Applied Language Learning, 5(1), 73-91.

Hofstede, G. (1991). Cultures and Organizations: Software of the Mind. London: McGraw- Hill. Hymes, D. (1971). Sociolinguistics and the ethnography of speaking. In Ardener, E. (ed.) Social anthropology and language. London: Tavistock Publications, 47-95.

Hymes, D. H. (1972). On communicative competence. In B. Pride \& J. Holmes (Eds.), Sociolinguistics (pp. 269-293). Harmondsworth: Penguin.Intachakra, S. (2004). 'Contrastive Pragmatics and Language Learning: Apologies and Thanks in English and Thai', Regional Language Centre Journal 35: 37-62.

Kasper, G. and K. R. Rose (2002). Pragmatic development in a second language, Oxford: Wiley-Blackwell.

Komter, A. E. (2004). Gratitude and gift exchange. In R. A. Emmons, \& M. E. McCullough (Eds.), The psychology of gratitude, 195-212. New York: Oxford University Press.

Kumar, I. (2001). Expressions of politeness and gratitude: Towards a general theory. New Delhi: Munshiram Manoharlal Publishers.

Leech, G. (1983). Principles of pragmatics. London: Longman.

Locher, M. A. and Watts, R. J. (2005). Politeness theory and relational work. Journal of Politeness Research 1: 9-33.

Miles, M.B. Huberman. A.M. (1994).Qualitative data analysis: A new sourcebook of methods. Newbury Park, CA: Sage.

Morrow, J. A. 2006. Arabic, Isläm, and the Alläh lexicon: how language shapes our conception of God, Lewiston: Edwin Mellen P.

Morsi, R. (2010). Speech act of thanking in Egyptian Arabic. Unpublished MA disertation. Ball State University Muncie. India.

Nydell, MX. (1987). Understanding Arabs: A guide for Westerners. Bangor, ME: Intercultural Press.

Okamoto, S., \& Robinson, W. P. (1997). Determinants of gratitude expressions in England. Journal of Language and Social Psychology, 16(4), 411-433.

Pablos-Ortega, C. (2010). Attitudes of English Speakers towards Thanking in Spanish. Pragmatics 20:2.149-170.

Samarah, A. Y. (2010). Views of Apology in Linguistics: Examples of Arabic Culture. Journal of Language and Literature. 3 57-73.

Scollon, R. and S. B. K. Scollon (1995). Intercultural communication: A discourse approach. Oxford: Blackwell.

Searle, J. R. (1969). Speech acts: An essay in the philosophy of language. Cambridge: Cambridge University Press.

Shouby, E. (1951). The influence of the Arabic language on the psychology of the Arabs. Middle East Journal, 5, 284 302.

Smith-Hefner, N. (1988).Women and politeness: the Javanese example. Language in Society, 17(4), 535-554.

Spencer-Oatey, H. (2005). (Im)Politeness, face and perceptions of rapport: Unpacking their bases and interrelationships. Journal of Politeness Research 1: 95-119.

Strauss, A. (1987). Qualitative Analysis for Social Scientists. New York: Cambridge University Press.

Strauss, A., \& Corbin, J. (1990). Open coding. In A. Strauss, \& J. Corbin (Eds.), Basics of qualitative research: Grounded theory procedures and techniques (2nd ed., pp. 101-121). Thousand Oaks, CA: Sage.

Suleiman, M. W. (1973). The Arabs and the West: Communication gap. In M. H. Posser (Ed.), Intercommunication among nations and people (pp. 278-303). New York: Harper \& Row.

Takahashi, T., \& Beebe, L. M. (1993). Cross-linguistic influence in the speech act of correction. In G. Kasper \& S. Blum-Kulka (Eds.), Interlanguage pragmatics (pp. 138-158). New York: Oxford University Press.

Wolfson, N. (1986). Compliments in Cross-Cultural Perspective. Tesol Quarterly, 15, 117-124.

Wolfson, N. (1989). Perspectives: Sociolinguistics and TESOL. Cambridge: Newbury House.

Yang, W. (1986). Korean Mind. Seoul: Tamgu Dang Publishing.

Zaharna, R. S. (1995). Understanding cultural preferences of Arab communication patterns. Public Relations Review, $21,241-255$ 